\title{
PENGEMBANGAN MEDIA PEMBELAJARAN MENGGUNAKAN POWERPOINT DISERTAI VISUAL BASIC FOR APPLICATION MATERI JARAK PADA BANGUN RUANG KELAS $X$
}

\author{
Siti Marfuah, Zulkardi, dan Nyimas Aisyah \\ sitmarf@gmail.com \\ Pendidikan Matematika - FKIP Universitas Negeri Sriwijaya \\ 2016
}

\begin{abstract}
Abstrak
Penelitian ini bertujuan: (1) menghasilkan media pembelajaran menggunakan powerpoint disertai visual basic for application materi jarak pada bangun ruang yang valid dan praktis di kelas $\mathrm{X}$, dan (2) mengetahui efek potensial dari pengembangan media pembelajaran menggunakan powerpoint disertai visual basic for application materi jarak pada bangun ruang di kelas X. Jenis penelitian yang digunakan adalah Design Research tipe Development Study. Subjek penelitian ini adalah siswa kelas X SMA Negeri 4 Palembang tahun ajaran 2014/2015. Teknik pengumpulan data adalah dengan walkthrough, tes, angket, dan wawancara. Hasil dari penelitian ini adalah: (1) Penelitian ini telah menghasilkan media pembelajaran menggunakan powerpoint disertai visual basic for application materi jarak pada bangun ruang yang valid dan praktis. (2) media pembelajaran yang dikembangkan memiliki efek potensial terhadap hasil belajar dan sikap positif siswa.
\end{abstract}

Kata Kunci: pengembangan, media pembelajaran, powerpoint, jarak pada bangun ruang

\begin{abstract}
This design research typed Development Study aims to: (1) develop valid and practical learning media using power point and visual basic for application for Distance in three-dimensional objects topic in class $\mathrm{X}$, and (2) to determine the potential effects media developed by using power point and visual basic for application for Distance in three-dimensional objects topic in class X. The subjects were students of class X SMA Negeri 4 Palembang academic year 2014/2015. Data were collected through walkthrough, tests, questionnaires, and interviews. The study results show that (1) This research has produced valid and practical learning media using power point and visual basic for application for Distance in three-dimensional objects topic; (2) the learning media developed has potential effects on students' learning outcomes and students' positive attitude.
\end{abstract}

Keywords: development, learning media, powerpoint, distance in three-dimensional object

\section{Pendahuluan}

Materi geometri merupakan materi yang sangat penting untuk dipelajari karena materi geometri termasuk salah satu domain konten soal yang diteskan pada PISA. Pendapat ini didukung oleh Wardhani dan Rumiati (2011) yang menyatakan bahwa domain konten soal yang diteskan PISA kepada siswa di Indonesia salah satunya adalah geometri. Sub-sub komponen konten yang diteskan yaitu perubahan dan keterkaitan, ruang dan bentuk, kuantitas, dan ketidakpastian data. 
Selain itu juga dikatakan oleh Wahyuni (2013) bahwa didalam Ujian Nasional, soal-soal terkait geometri khususnya dimensi tiga selalu muncul. Salah satu konsep yang selama tiga tahun terakhir ini selalu diujikan pada Ujian Nasional SMA adalah mengenai jarak pada bangun ruang dimensi tiga.

Pada dasarnya materi geometri mempunyai peluang yang lebih besar untuk dipahami siswa dibandingkan degan cabang matematika lainnya.Hal ini karena ide-ide geometri sudah dikenal oleh siswa sejak sebelum mereka masuk sekolah.Namun pada kenyataan di lapangan menunjukkan bahwa materi geometri kurang dikuasai oleh sebagian besar siswa.Masih banyak siswa yang mengalami kesulitan dalam belajar geometri khusunya jarak pada bangun ruang. Hal ini didasari dari hasil penelitian Kurniasari (2012) yang menyimpulkan bahwa presentase kesalahan pada konsep jarak adalah $57 \%$ atau dilakukan oleh 40 siswa dari 70 siswa dan presentase kesalahan pengabstrakan penentuan jarak pada bidang adalah $78 \%$ atau dilakukan 55 orang siswa dari 70 siswa. Data ini didukung juga oleh data yang diperoleh dari hasil observasi terhadap data ulangan harian siswa di SMAN 4 Palembang yang menunjukkan bahwa hasil belajar siswa pada materi jarak pada bangun ruang tidak cukup baik.Terdapat $87 \%$ siswa yang mendapatkan hasil belajar dibawah nilai ketuntasan belajar atau terdapat 33 siswa dari 38 siswa yang hasil belajarnya dibawah nilai ketuntasan.Tingginya hasil tingkat kesalahan dalam konsep jarak dan kesalahan dalam pengabstrakan menandakan bahwa siswa mengalami permasalahan dalam menyelesaikan soal geometri khususnya jarak pada bangun ruang.

Penggunaan teknologi informasi dan multimedia menjadi sebuah cara yang efektif dan efisien dalam menyampaikan informasi. Komputer merupakan salah satu teknologi informasi yang memiliki potensi besar untuk meningkatkan kualitas pembelajaran, khususnya dalam pembelajaran matematika.Hal ini juga sesuai dengan pendapat Arnold dan Lawson
(2003) yang menyatakan bahwa pembelajaran dengan menggunakan komputer dalam kelas matematika dapat membantu siswa untuk memahami konsep-konsep abstrak. Dengan demikian pengembangan proses pembelajaran matematika dapat dilakukan guru dengan memanfaatkan media komputer serta programprogram sederhana. Banyak jenis program komputer yang dapat dijadikan media penunjang dalam pembelajaran matematika di sekolah. Salah satu program diantaranya adalah Microsoft Powerpoint. Menurut Arsyad (2012) Microsoft Powerpoint merupakan salah satu software yang dirancang khusus untuk menampilkan program multimedia yang menarik, mudah dalam pembuatan, mudah dalam penggunaan. Berdasarkan hasil penelitian Sari (2014) menyimpulkan bahwa pemanfaatan powerpoint dalam pembelajaran dapat meningkatkan hasil belajar matematika. Oleh karena itu, dalam pembelajaran matematika khususnya konsep abstrak sebaiknya memanfaatkan media komputer seperti Microsoft Powerpoint.

Pengembangan media pembelajaran ini juga sesuai dengan kurikulum 2013.Pembelajaran kurikulum 2013 berbasis TIK (Teknologi Informasi dan Komunikasi). Paparan Menteri Pendidikan dan Kebudayaan tentang pengembangan kurikulum 2013 bahwa pembelajaran abad 21 berbasis TIK, dalam artian guru harus melek teknologi dimana guru harus mampu memanfaatkan TIK dalam proses pembelajaran (Afandi, 2014). Oleh sebab itu, dengan melakukan pengembangan media pembelajaran powerpointini diharapkan dapat membantu dalam memperjelas penyampaian materi sehingga dapat mempermudah siswa dalam memahami konsep pelajaran yang dalam penelitian mengenai bahasan jarak pada bangun ruang.

Penelitian ini juga didukung oleh penelitian sebelumnya tentang media pembelajaran matematika yang dikembangkan dengan komputer menggunakan Microsoft Excel memanfaatkan visual basic oleh Suhendra (2013) yang memberikan efek potensial terhadap 
aktivitas dan hasil belajar siswa. Selain itu, hasil penelitian yang dilakukan oleh Surmilasari (2013)di SMA Az-Zahra Palembang menyimpulkan bahwa dengan menggunakan media pembelajaran menggunakan powerpointmampu memberikan efek potensial terhadap hasil dan minat belajar siswa. Akan tetapi, dalam pengembangan Microsoft powerpoint tersebut tidak menyediakan fasilitas untuk melihat informasi dari pengguna setelah melakukan eksplorasi pembelajaran. Dengan kelemahan ini maka kemampuan belajar siswa tidak bisa dilihat secara langsung.

Oleh karena itu, peneliti akan mengembangkan media menggunakan powerpoint disertai visual basicfor application agar media tersebut dapat melihat gambaran kemampuan siswa saat proses pembelajaran secara langsung dan penggunaan visual basic for application pada powerpoint akan membuat media menjadi lebih interaktif. Pendapat ini juga didukung oleh Marchovitz (2004) yang menyatakan bahwa menambahkan sedikit bahasa pemrograman (VBA) pada powerpoint tradisional akan memberikan hasil yang banyak tidak hanya pada media tapi juga pada interaktivitas.

Berdasarkan uraian diatas rumusan masalah dalam penelitian ini adalah apakah media pembelajaran yang dikembangkan valid dan praktis, serta Bagaimana efek potensial yang muncul dari pengembangan media pembelajaran menggunakan powerpoint disertai visual basic for application materi jarak pada bangun ruang. Kemudian, tujuan penelitian ini adalah untuk menghasilkan media pembelajaran yang valid, praktis, dan memiliki efek potensial terhadap hasil belajar.

Selain itu, penelitian ini bermanfaat untuk siswa dalam pembelajaran materi jarak pada bangun ruang, sebagai media pembelajaran yang dapat digunakan guru dalam proses pembelajaran, memberikan sumbangan positif dalam pembelajaran di sekolah, dan dapat dijadikan referensi bagi peneliti lainnya.

\section{Metode Penelitian}

Dalam penelitian ini, metode yang digunakan adalah pengembangan atau development research tipe development study.Penelitian pengembangan ini terdiri dari tiga tahap yaitu analisis, desain, dan evaluasi (Akker, 1999). Pada tahap evaluasi, digunakan tahap-tahap Formative Evaluation menurut Tessmer (1993) dalam Zulkardi (2006).

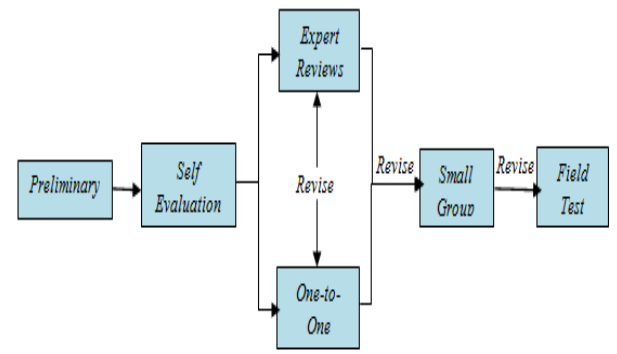

Gambar 1. Tahap-Tahap Formative EvaluationMenurut Tessmer (1993)dalam Zulkardi (2006)

Berikut adalah penjelasan masingmasing tahap formatif evaluation yang akan digunakan pada penelitian ini.

a. Expert Review

Pada tahap ini, LKS yang telah dikembangkan oleh peneliti diberikan pada 5 orang pakar, yang terdiri dari 4 orang dosen dan 1 orang guru senior mata pelajaran matematika yang akan menjadi validator untuk memvalidasi media pembelajaran.

b. One-to-One

Pada tahap ini peneliti melakukan uji coba kepada dua orang siswa kelas X SMA. Tahap ini dilakukan untuk melihat sejauh mana media pembelajaran yang dikembangkan dapat dipahami dan dimengerti oleh siswa.

\section{c. Small Group}

Pada tahap ini peneliti menguji cobakan prototype kedua yaitu hasil revisi dari komentar dan saran pada tahap expert review dan one to one di tahap small group. Pada tahap ini peneliti memberikan media pembelajaran kepada sekelompok siswa SMA yang bukan subjek penelitian untuk melihat kepraktisan media pembelajaran yang telah dikembangkan. 


\section{d. Field Test}

Pada tahap ini peneliti menguji cobakan prototype ketiga ke lingkup yang lebih luas yaitu siswa kelas X SMA Negeri 4 Palembang .Pada tahap ini peneliti ingin melihat efek potensial dari pengembangan media pembelajaran yang telah dilakukan.

Teknik pengumpulan data dalam penelitian ini adalah walkthrough, tes, wawancara dan angket.Data yang diperoleh dari walkthrough, dan wawancara dianalisis secara deskriptif, data tes dianalisis dengan menggunakan pedoman penskoran dan hasil angket dianalisis dengan menggunakan skala likert.

\section{Hasil dan Pembahasan}

Penelitian ini dilakukan dalam dua tahapan, yaitu tahap preliminary dan tahapan formatif evaluation. Pada tahapan preliminary meliputi analisis dan desain. Pada tahap analisis, peneliti menganalisis karakteristik siswa kelas X. Diketahui bahwa siswa kelas X masih memiliki kesulitan dalam menentukan jarak pada bangun ruang.Kemudian peneliti mendesain suatu wadah berupa media pembelajaran agar siswa dapat menentukan jarak pada bangun ruang.Adapun konsep desain awal dari media pembelajarannya tertera di bawah ini.

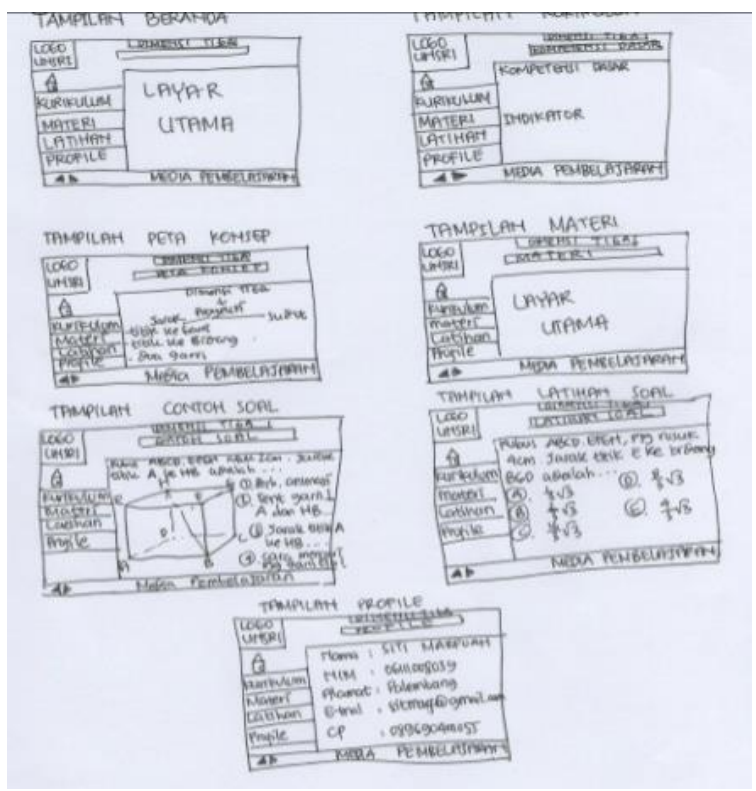

Gambar 2. Konsep awal media
Tahapan selanjutnya yaitu tahapan formatif evaluation, media pembelajaran yang sudah peneliti desain melewati tahap formatif evaluation yang terdiri dari lima tahap yaitu self evaluation, expert review, one-to-one, small group, dan field test.

Proses revisi dilakukan pada setiap tahap sehingga diperoleh media pembelajaran menggunakan powerpoint disertai visual basic for application yang valid, praktis dan memiliki efek potensial.

Pada tahap self evaluation peneliti mengevaluasi kembali hasil dari desain media pembelajaran yang dibuat.Peneliti mereview kembali tombol-tombol yang belum berfungsi pada setiap tampilan halaman media.

Kemudian peneliti merubah beberapa bagian kalimat yang masih terdapat kesalahan kata dan kesalahan penulisan kalimat.Dan juga peneliti memerikasa kembali contoh-contoh soal yang dibuat karena terjadi beberapa kekeliruan penghitungan.Hasil dari revisi ini dinamakan prototype pertama.Berikut tampilan beberapa slide dari prototype pertama.

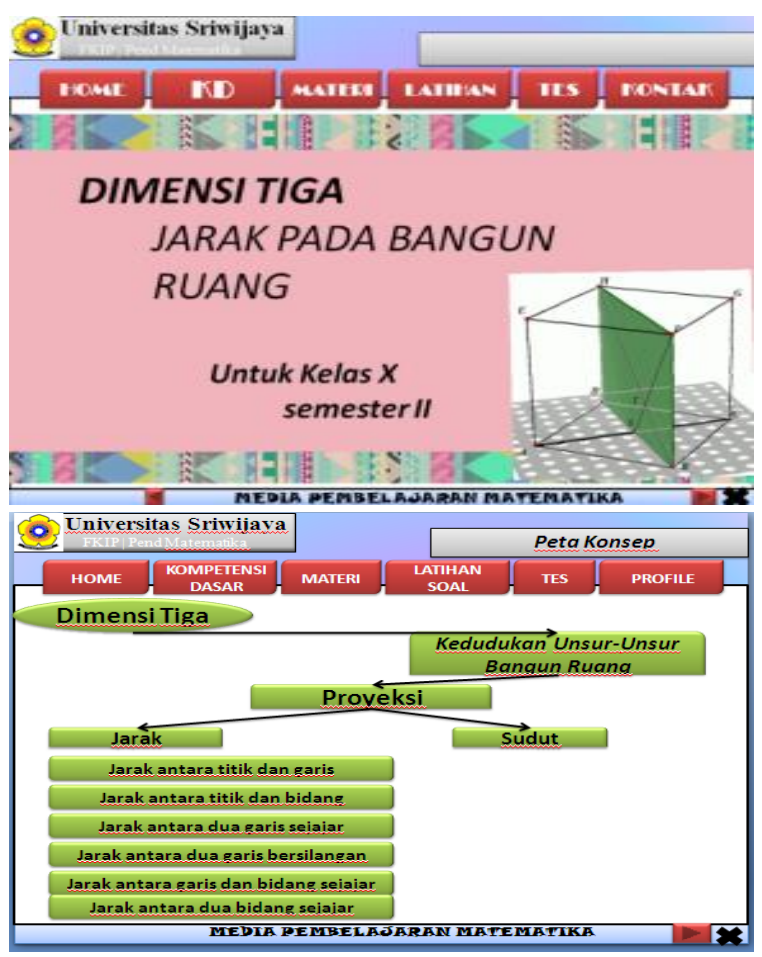

Gambar 3. Cuplikan prototype pertama 
Pada tahap expert review prototype pertama diberikan kepada lima orang pakar dan satu orang guru. Berikut hasil revisi pada tahap expert review.

Tabel 1. Hasil Revisi Expert Review

\begin{tabular}{|c|c|}
\hline Saran dan Komentar & Keputusan Revisi \\
\hline $\begin{array}{l}\text { On click di setiap } \\
\text { page di off kan }\end{array}$ & $\begin{array}{l}\text { On click setiap page } \\
\text { sudah di off kan }\end{array}$ \\
\hline $\begin{array}{l}\text { Hilangkan tombol } \\
\text { Next dan Back yang } \\
\text { tidak digunakan. }\end{array}$ & $\begin{array}{l}\text { Sudah dihilangkan } \\
\text { tombol next dan back } \\
\text { yang tidak digunakan }\end{array}$ \\
\hline $\begin{array}{l}\text { Perbaiki dan lebih } \\
\text { difokuskan pada } \\
\text { materi di bagian peta } \\
\text { konsep }\end{array}$ & $\begin{array}{l}\text { Sudah diperbaiki peta } \\
\text { konsep dengan } \\
\text { memfokuskan pada } \\
\text { materi jarak saja }\end{array}$ \\
\hline $\begin{array}{lr}\text { Beri penjelasan } \\
\text { terhadap } & \text { definisi } \\
\text { jarak pada slide } \\
\text { ilustrasi }\end{array}$ & $\begin{array}{l}\text { Sudah ditambahkan } \\
\text { definisi jarak pada slide } \\
\text { ilustrasi }\end{array}$ \\
\hline 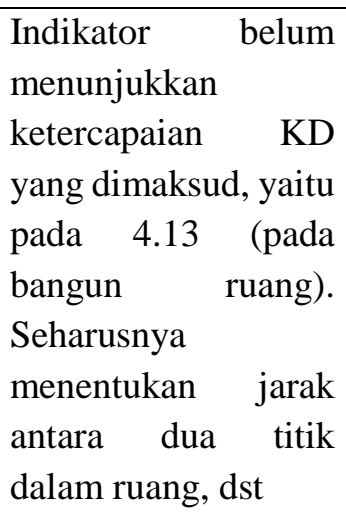 & $\begin{array}{l}\text { Sudah diperbaiki } \\
\text { indikator sesuai dengan } \\
\text { KD } 4.13\end{array}$ \\
\hline $\begin{array}{l}\text { Perbaiki } \\
\text { penyelesaian luas } \\
\Delta \text { GBA }\end{array}$ & Sudah diperbaiki \\
\hline $\begin{array}{l}\text { Perbaiki kalimat } \\
\text { pada contoh soal } \\
\text { jarak titik ke bidang }\end{array}$ & $\begin{array}{l}\text { Kalimat pada contoh } \\
\text { soal sudah diperbaiki }\end{array}$ \\
\hline $\begin{array}{l}\text { Perbaiki jawaban } \\
\text { pada contoh soal dua } \\
\text { garis sejajar }\end{array}$ & Sudah diperbaiki \\
\hline 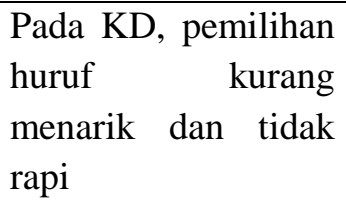 & $\begin{array}{l}\text { Pemilihan huruf sudah } \\
\text { diganti }\end{array}$ \\
\hline
\end{tabular}

Setelah melakukan tahap expert review dilanjutkan dengan one-to-one dengan cara memberikan media pembelajaran kepada dua orang siswa. Berikut hasil revisi pada tahap oneto-one.

Tabel 2. Hasil Revisi One-to-one

\begin{tabular}{|l|l|}
\hline $\begin{array}{l}\text { Saran dan } \\
\text { Komentar }\end{array}$ & Keputusan Revisi \\
\hline $\begin{array}{l}\text { Gambar dan } \\
\text { tulisan pada kubus } \\
\text { kurang jelas }\end{array}$ & $\begin{array}{l}\text { Gambar dan tulisan } \\
\text { kubus sudah diperbaiki. }\end{array}$ \\
\hline $\begin{array}{l}\text { Warna untuk } \\
\text { gambar agar lebih } \\
\text { cerah }\end{array}$ & $\begin{array}{l}\text { Warna sudah diganti } \\
\text { menjadi lebih cerah. }\end{array}$ \\
\hline
\end{tabular}

Berikut contoh salah satu slide setelah dilakukan revisi pada tahap one-to-one.

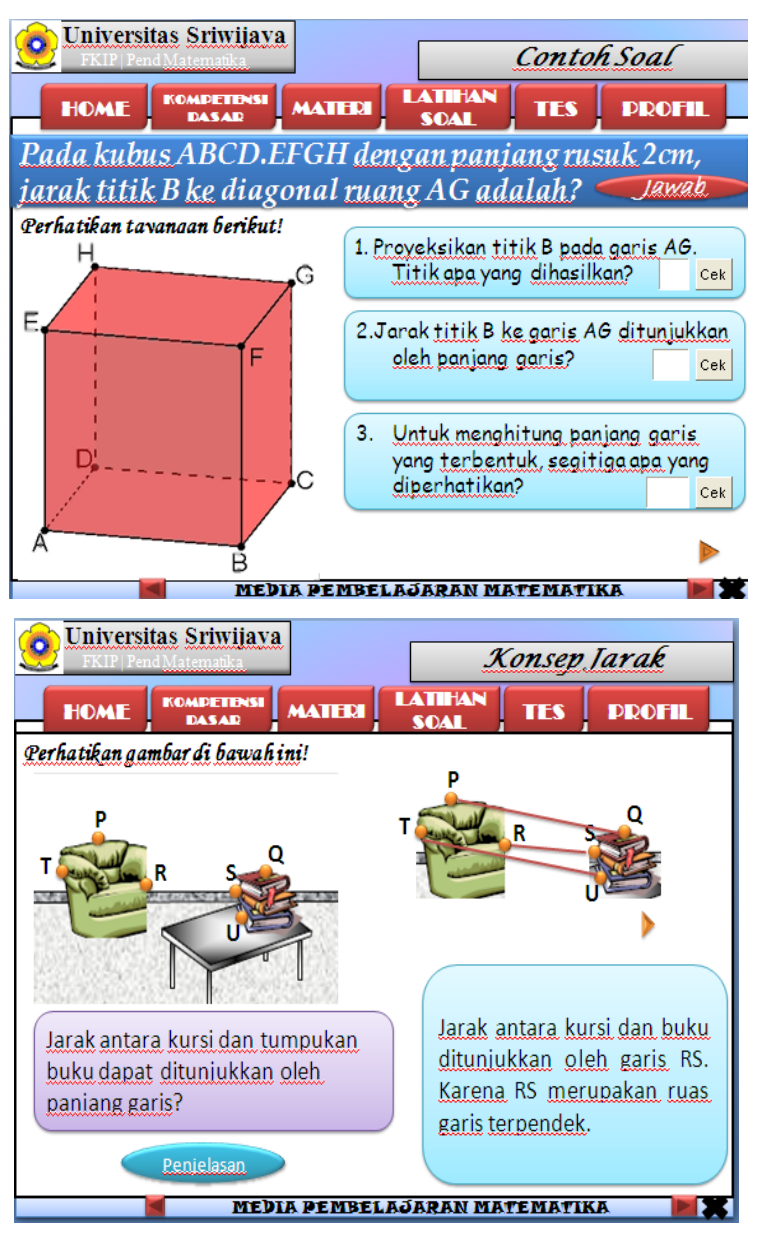




\section{Gambar 4. Hasil Revisi Tahap One-to-one}

Setelah dilakukan tahap expert review dan one-to-one diperoleh media pembelajaran yang valid. Media pembelajaran yang telah valid, dilanjutkan dengan tahap small group. Pada tahapan small group, peneliti memberikan media pembelajaran yang telah valid melalui tahap expert review dan one-to-one kepada lima orang siswa.

Setelah dilakukan tahap small group didapatlah hasil media pembelajaran yang termasuk dalam kategori valid dan praktis. Berikut adalah beberapa contoh slide pada media pembelajaran

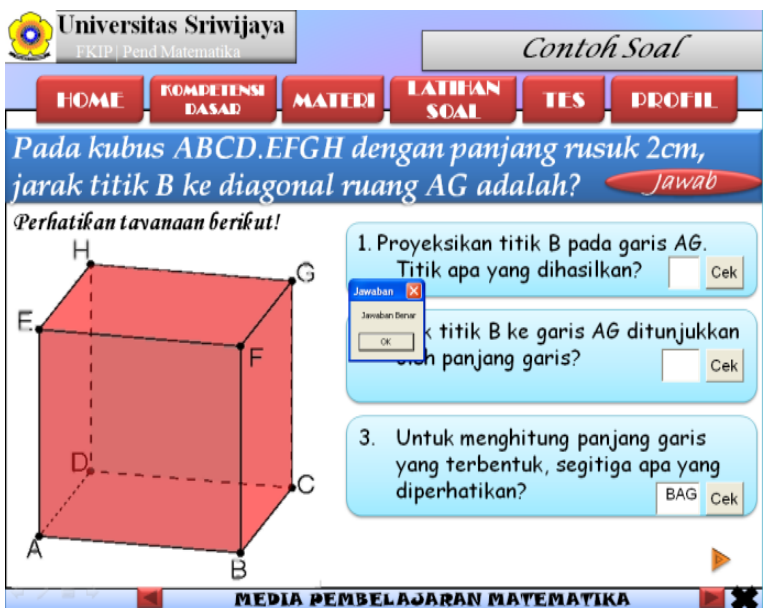

Gambar 5. Media pembelajaran menggunakan powerpoint disertai visual basic for application

Media pembelajaran yang telah dikembangkan praktis, hal ini terlihat pada tahap small group. Pada tahap small group, siswa dapat menggunakan media pembelajaran dengan baik dan mudah, hanya mengklik setiap pilhan yang tersedia pada powerpoint disertai visual basic for application. Misalkan pada proses pembelajaran, siswa ingin mengecek jawaban nya, siswa dengan mudah hanya mengklik tombol cek maka akan keluar hasil jawaban siswa tersebut, apakah benar atau salah. Kepraktisan media pembelajaran juga dapat dilihat pada saat siswa menggunakan media pembelajaran powerpoint disertai visual basic for application, siswa dapat memahami permasalahan yang ada pada pertanyaan soal berupa menentukan jarak pada bangun ruang dengan hanya melihat dari gambar animasi kubus. Selain itu juga, siswa dapat mengerjakan soal-soal pada media pembelajaran. Sehingga media pembelajaran menggunakan powerpoint disertai visual basic for application dapat diterima untuk proses pembelajaran di sekolah.

Tahap selanjutnya adalah field test, pada tahap ini peneliti mengujicobakan media pembelajaran yang valid dan praktis di kelas $\mathrm{X}$ SMAN 4 Palembang untuk melihat efek potensial media pembelajaran. Untuk melihat efek potensial terhadap hasil belajar, peneliti melakukan analisis terhadap hasil tes siswa. Dari hasil tes siswa setelah proses pembelajaran, diketahui bahwa sebanyak 30 siswa (83\%) mendapatkan nilai $\geq 2,67$ dan sebanyak 6 siswa (17\%) mendapatkan nilai $<2,67$. Hal ini menunjukkan bahwa media pembelajaran yang telah dikembangkan memiliki efek potensial terhadap hasil belajar siswa karena nilai tes siswa yang memperoleh nilai lebih dari 2,67 sebanyak lebih dari $75 \%$.

Dan untuk melihat efek potensial terhadap sikap positif siswa, peneliti memberikan angket dan melakukan wawancara. Hasil dari angket yang peneliti berikan kepada siswa yang sudah dianalisis dengan menggunakan skala likert, diketahui bahwa semua indikator di dalam angket menunjukkan persentase $>61 \%$, ini berarti media pembelajaran yang diberikan kepada siswa menunjukkan sikap positif.

Sikap positif siswa terhadap media pembelajaran didukung juga dengan data wawancara. Hasil dari wawancara diperoleh bahwa siswa kelas X SMA Negeri 4 Palembang menyukai dan merasa tertarik belajar menggunakan media pembelajaran menggunakan powerpoint disertai visual basic for application karena materi menjadi mudah dipahami, penjelasannya tidak membosankan, banyak warna dan terdapat gambar yang bergerak. 


\section{Penutup}

Berdasarkan hasil dan pembahasan, diperoleh bahwa media pembelajaran yang dikembangkan valid dan praktis. Kevalidan media pembelajaran berdasarkan isi, konstruk, dan bahasa. Dari segi isi, media pembelajaran powerpoint disertai visual basic for application yang peneliti kembangkan telah sesuai dengan Kompetensi Dasar dan indikator pada kurikulum 2013 dan sesuai dengan tujuan pembelajaran. Adanya kejelasan alur pembelajaran yang sesuai pada peta konsep. Dari segi konstruk, media pembelajaran yang dikembangkan sudah tersusun dengan baik sesuai dengan Akker (1999). konstruk media pembelajaran ini valid dengan sesuainya media pembelajaran dengan kaidah dalam pembuatan powerpoint, adanya interaktifitas ketika siswa melakukan proses pembelajaran, adanya kejelasan umpan balik pada saat proses pembelajaran menggunakan powerpoin, kualitas tampilan yang menarik yang didukung adanya gambar animasi kubus dan komposisi warna yang menarik. Sedangkan berdasarkan bahasa, media pembelajaran dengan powerpoint disertai visual basic for application yang dikembangkan telah menggunakan bahasa yang baik dan benar dimana tidak ada siswa yang salah pengertian dan mempunyai penafsiran ganda ketika membacanya.

Media pembelajaran yang telah dikembangkan praktis, hal ini terlihat pada tahap small group. Pada tahap small group, siswa dapat menggunakan media pembelajaran dengan baik dan mudah, hanya mengklik setiap pilhan yang tersedia pada powerpoint disertai visual basic for application. Kepraktisan media pembelajaran juga dapat dilihat pada saat siswa menggunakan media pembelajaran powerpoint disertai visual basic for application, siswa dapat memahami permasalahan yang ada pada pertanyaan soal berupa menentukan jarak pada bangun ruang dengan hanya melihat dari gambar animasi kubus.

Media Pembelajaran yang dikembangkan memiliki efek potensial terhadap hasil belajar, dengan nilai tes siswa yang bernilai
2,67 atau lebih sebanyak 83\% atau 30 siswa. Dan memiliki efek potensial terhadap sikap positif dengan persentase sikap siswa lebih dari $61 \%$ yang termasuk ke dalam kategori sikap siswa yang positif terhadap media pembelajaran menggunakan powerpoint disertai visual basic for application.

Berdasarkan hasil penelitain yang telah dilakukan, Adapun beberapa saran dari peneliti setelah melaksanakan penelitian ini: untuk siswa disarankan untuk lebih memahami lagi tentang materi segitiga agar lebih mudah memahami materi jarak pada bangun ruang; Untuk guru, disarankan agar pembelajaran dengan menggunakan media pembelajaran sesuai dengan waktu pada RPP; Untuk calon peneliti, disarankan agar dapat mengembangkan media pembelajaran menggunakan powerpoint disertai visual basic for application dengan menambahkan materi prasyarat pada awal pembelajaran

\section{Ucapan Terima Kasih}

Penulis mengucapkan terima kasih kepada Bapak Prof. Sofendi, M.A., Ph.D., selaku Dekan FKIP UNSRI, Bapak Dr. Ismet, M.Si, selaku Ketua Jurusan Pendidikan MIPA dan Ibu Dra. Cecil Hiltrimartin, M.Si selaku Ketua Program Studi Pendidikan Matematika yang telah member kemudahan dalam pengurusan administrasi penulisan skripsi kesempatan pada tim peneliti untuk melakukan penelitian ini.

\section{Referensi}

Afandi, R. 2014. Implementasi Kurikulum 2013 dalam Mempersiapkan Sumber Day Manusia Indonesia Menghadapi "Masyarakat Ekonomi ASEAN".Prosiding Seminar Nasional Pendidikan. Pascasarjana Unesa ISSN : 2407-1293 Halaman 109-117.

Akker, J.V.D. 1999. Principles and Methods of Development Research dalam (Eds). Design Approches and Tools in Education and Training. Dordrecht: Klower Academic Publisher. 
Arnold, L dan Lawson, M 2003. Spatial Problem-Solving in Year 7 Mathematics An Examination of the Effects of Use of a Computer-Mediated Software Program. Mathematics Education Research Journal th 2003, Vol 15, No2,187-202.

Arsyad, A. 2012.Media Pembelajaran. Jakarta:PT Raja Grafindo.

Kurniasari, I. 2013. Identifikasi Kesalahan Siswa Dalam Menyelesaikan Soal Geometri Materi Dimensi Tiga Kelas X IPA SMA. Prosiding Jurusan Pendidikan Matematika FMIPA UNY. Yogyakarta ISBN : $978-979-16353-9-4.4$.

Marchovitz, D.M. 2004. Powerful Powerpoint for Educators: Using Visual Basic for Application to Make Powerpoint Interactive. Wetsport: Libraries Unlimited.

Sari, M.K .2014. Pengembangan Materi Ajar Matematika Berbantuan Komputer pada Subpokok Bahasan Volume Benda Putar di Kelas XII. Skripsi.Palembang: Universitas Sriwijaya.

Suhendra, S. 2013. Pengembangan Bahan Ajar Sistem Persamaan Linier dengan Microsoft Excel di Sekolah Menengah Atas. Tesis S2. Palembang: PPS Universitas Sriwijaya.

Surmilasari, N. 2013.Pengembangan Multimedia pada Pokok Bahasan Menentukan Jarak Pada Bangun Ruang di Kelas X SMa. Tesis S2. Palembang: PPS Universitas Sriwijaya.

Tessmer, M. 1993. Planning and Conducting Formative Evaluations. Philadelphia: Kogan Page.

Wahyuni, D. 2013. Desain Didaktis Konsep Jarak Dalam ruang Dimensi Tiga Dengan Pendekatan Kontekstual Pada Pembelajaran Matematika SMA Kelas X. Skripsi. Bandung: FPMIPA Universitas Pendidikan Indonesia.

Wardhani, S \& Rumiati.2011. Instrumen Penilaian Hasil Belajar Matematika SMP:
Belajar dari PISA dan TIMSS. Kemendiknas.PPPPTK.

Zulkardi.2006. Formative Evaluation :What, why, when, and how. (online) Tersedia pada

http://www.oocities.org/zulkardi/books. html. Diakses tanggal 25 Mei 2015 